\title{
Laparoscopic Sleeve Gastrectomy and Crural Repair as a Treatment of Morbid Obesity Associated with Gastroesophageal Reflux
}

\author{
Sameh Gabr Attia
}

M.D., Assistant Professor, Department of surgery, Faculty of Medicine, Alazhar University, Cairo-Egypt

\section{Type of article: Original}

\begin{abstract}
Objective: The aim of this study was to evaluate the Laparoscopic Sleeve Gastrectomy (LSG) with simultaneous crural repair in treatment of morbid obesity associated with gastroesophageal reflux disease.

Methods: This prospective observational study was carried out from September 2012 to July 2016 in Al-Azhar University Hospital (Egypt). The study was conducted on 53 patients, 14 males (26.4\%) and 39 females (73.6\%) with the mean age 36.2 years (range 18-52 years), presenting with morbid obesity and reflux disease either symptomatic patients or asymptomatic (Endoscopic \& Manometric), their mean Body Mass Index (BMI) was $50.1 \mathrm{~kg} / \mathrm{m}^{2}$ (range $40-62 \mathrm{~kg} / \mathrm{m}^{2}$ ), who underwent LSG and antireflux procedure (crural repair).

Results: Excess weight Loss (EWL); the mean EWL at 6 months postoperatively was $46.3 \%$, at 12 months was $54 \%$, and at 18 months was $61 \%$. Also, we found that, preoperative co-morbidities are resolved by $53 \%$ and improved by $23 \%$. Reflux symptoms were absent in 30 patients $(56 \%)$, improved in 14 patients $(26.4 \%)$, but persistent in 7 patients $(13.2 \%)$.

Conclusion: Laparoscopic crural closure, during LSG, represents a valuable option for the treatment of morbid obesity and gastroesophageal reflux, and can result in favorable outcomes in terms of weight loss and gastroesophageal reflux disease (GERD) symptoms control.
\end{abstract}

Keywords: Morbid obesity, Reflux esophagitis, Sleeve gastrectomy, Hiatal repair, Weight loss

\section{Introduction}

Obesity worldwide is steadily increasing, and in the US, it has been estimated that if the current trend continues, $40 \%$ of Americans will be obese by 2025 . One of the alarming factors of the obesity epidemic is that $15 \%$ of children and adolescents are obese $\left(\mathrm{BMI}>95^{\text {th }}\right.$ percentile on the Centres for Disease Controls and Prevention standard charts) and more than $20 \%$ are at risk (BMI $>85^{\text {th }}$ percentile) (1). Premature mortality and many chronic conditions, including hypertension, type II diabetes mellitus, heart disease, stroke, osteoarthritis, obstructive sleep apnea (OSA) are attributed to obesity, as well as a number of cancers and depression. Obesity associated with GERD presents a major increase in incidence worldwide. Obesity increases the intra-abdominal pressure, and so they are often associated $(3,4)$. Around $50 \%-70 \%$ of patients who undergo bariatric surgery have reflux symptoms, and symptomatic Hiatus Hernia $(\mathrm{HH})$ can account for only $15 \%$ of patients with a BMI $>35 \mathrm{~kg} / \mathrm{m}^{2}$ (5). In concomitance with the rise in numbers of obesity there has been a renewed interest in the surgical treatment of morbid obesity in recent years. The reasons for the sharp increase in bariatric surgery are the unfavourable results obtained with non-surgical treatment, the significantly effective reports on durable weight loss after surgery and the consequent increase in patient demand following the widespread positive media attention on surgical treatment. Predicted weight-loss, improved quality of life, relief of co-morbidities, preference of patients, technical considerations and risks, behaviour of patient, and changes in composition of the body are the most important factors to consider when contemplating bariatric procedure. LSG is a relatively new surgical approach in the weight loss surgeon's armamentarium, but one that has seen growth in popularity, because of the perceived simplicity of the surgical technique, resolution of co-morbidities, and excellent weight loss outcomes (9). LSG was initially proposed

\section{Corresponding author:}

Assistant Professor Dr. 3557Sameh Gabr Attia, Department of surgery, Faculty of Medicine, Alazhar University, Cairo-Egypt, tel.: +201222114628, E-mail: Samehgabr70@gmail.com

Received: October 14, 2016, Accepted: December 16, 2016, Published: January 2017

iThenticate screening: December 16, 2016, English editing: January 02, 2017, Quality control: January 08, 2017

(C) 2017 The Authors. This is an open access article under the terms of the Creative Commons Attribution-NonCommercialNoDerivs License, which permits use and distribution in any medium, provided the original work is properly cited, the use is non-commercial and no modifications or adaptations are made. 
as a first step procedure in high risk patients followed by second step Bilo-Pancreatic Diversion-Duodenal Switch (BPD-DS) or Roux-en-Y gastric bypass (RYGBP), LSG has, with minimally invasive techniques and an increase in surgical experience, become widely considered as a primary restrictive bariatric procedure (10). The indications for LSG as a primary procedure were published in 2008, with significant 3-and 5-years data and experience justifying its recommendation by the American Society for Metabolic and Bariatric Surgery as an approved bariatric procedure (11). The purpose of this research was the evaluation of LSG with simultaneous crural repair in treatment of morbid obesity associated with gastroesophageal reflux disease.

\section{Material and Methods}

This study was a prospective, observational study performed at the department of surgery, Al-Azhar University Hospitals. It was carried out on 53 patients, 14 males (26.4\%) and 39 females $(73.6 \%)$ with the mean age 36.2 years (range 18-52 years), presenting with morbid obesity and reflux disease, either symptomatic patients or asymptomatic (Endoscopic \& Manometric), whose mean BMI was $50.1 \mathrm{~kg} / \mathrm{m}^{2}$ (range 40-62 kg/m²), underwent LSG and antireflux procedure (crural repair).

\subsection{Selection criteria}

\subsubsection{Inclusion criteria}

Inclusion criteria were morbidly obese patients $\left(\mathrm{BMI} 40-62 \mathrm{~kg} / \mathrm{m}^{2}\right.$ ), absence of endocrinal causes, non-sweet eaters, no previous upper Gastro-intestinal tract surgery (GIT), and patients with reflux esophagitis either symptomatic or asymptomatic.

\subsubsection{The Exclusion criteria}

Exclusion criteria were morbidly obese patients with no reflux on preoperative studies, sweet eaters, patients with previous upper GIT surgeries, patients with psychological troubles, patients presenting esophageal motility problems (other than those related to GERD). Also, patients with Barrett's esophagus were not included. All patients were admitted to the surgical department of Al-Azhar University Hospital and referred from outpatient clinics in the period between September 2012 and July 2016. The study was approved by the local ethics committee of the surgery department. Informed consent was granted from all patients. All patients in our study underwent history taking, complete clinical examination, detailed investigations, especially upper gastrointestinal endoscopy and esophageal manometry. A number of patients were also submitted to contrasted gastroesophageal radiography using oral barium especially those whose endoscopic exams revealed the existence of hiatal hernias. The operative time and hospital stay were evaluated. All patients were followed up for 18 months. During hospital stay and follow up period, all patients were evaluated for development of morbidities (leak, stricture, vomiting, bleeding or wound complications), monitoring of EWL, evaluation of reflux symptoms, and evaluation of preoperative co-morbidities (diabetes, hypertension, OSA). Post-operatively, since most did not present symptoms, endoscopy and manometry were not routinely applied.

\subsection{Surgical technique}

After prophylactic antibiotic and general endo-tracheal anesthesia were administered, the patient is placed in the supine position (split-leg and reverse Trendelenburg position). Port-sites incisions and insertion of ports (5 ports) were done. Mobilization of distal esophagus and gastroesophageal junction were done by using a laparoscopic harmonic scalpel to get a 4-cm tension-free intra-abdominal esophagus. Posterior crural repair was performed with 2-3 interrupted sutures of 2-0 Ethibond. LSG was started by dividing the greater omentum with the ultrasonic shears at a point $5-6 \mathrm{~cm}$ from the pylorus along the greater curvature. The gastroepiploic artery branches are divided near the gastric wall. Cephalad continues, followed by the division of the gastric vessels which are carried out up to the fundus. Division of the posterior fundic vessels is also carried out. Next, the angle of His is dissected from the left crus of the diaphragm. Following greater curvature dissection, lyses to all adhesions in the lesser sac is carried out, leaving the posterior aspect of the antrum free. The LSG then commences with sequential firings of $60-100 \mathrm{~mm} / 4.8$ $\mathrm{mm}$ linear staplers close to a 40-Fr bougie which follows the lesser curvature. Once the gastrectomy is completed, the excised stomach is retrieved outside through the right-side port wound. Finally, to test the staple line for leaks and measure the gastric capacity, we carry out a methylene-blue test through an orogastric tube with the proximal duodenum clamped with long intestinal forceps. If bleeding or leaks are identified, over-sewing the staple line with an absorbable running suture (vicryl) can be carried out.

\subsection{Postoperative follow up}

Patients are cared for on the ward, unless significant pre-existing cardiopulmonary disease, BMI $>60 \mathrm{~kg} / \mathrm{m}^{2}, \mathrm{OSA}$ and intraoperative complications warrant Intensive Care Unit (ICU) care. Anti-coagulant as a prophylaxis of DVT 
was used. Patients are usually taking oral fluids and then feeding on the third postoperative day after successful leak test, and discharged on the fourth postoperative day. The follow up was scheduled weekly for one month, and then monthly, the EWL was recorded at $6 \mathrm{t}, 12$, and $18 \mathrm{t}$ months postoperatively.

\section{Results}

\subsection{Preoperative and general findings}

Of 53 patients; 14 patients were males (26.4\%), 39 were females (73.6\%). 47 patients had reflux symptoms (88.6\%) while 6 patients had asymptomatic reflux (11.4\%). 5 patients were super-super obese (BMI was $>60 \mathrm{~kg} / \mathrm{m}^{2}$ ) (9.4\%). 3 patients had history of DVT (5.6\%). 5 patients had OSA $(9.4 \%) .9$ patients were diabetic (16.9\%). 11 patients were hypertensive (20.7\%) (Table1). All patients were of grade I or II of American Society of Anesthesiologists (ASA) grades, (ASA physical status classification system is a system for assessing the fitness of patients before surgery, the society adopted six categories; grade I - normal healthy patient, grade II - patient with mild systemic disease). The median operative time was 115 minutes (range 90-180 min). The mean postoperative hospital stay was 4.2 days (range 3-6 days).

Table 1. Patient's demographics

\begin{tabular}{|c|c|c|c|}
\hline \multicolumn{2}{|l|}{ Parameters } & \multicolumn{2}{|c|}{ Values } \\
\hline \multirow{2}{*}{ Sex; n (\%) } & Male & 14 & $(26.4)$ \\
\hline & Female & 39 & (73.6) \\
\hline \multicolumn{2}{|l|}{ Age (Year) } & \multicolumn{2}{|c|}{36.2 (range: $18-52$ ) } \\
\hline \multicolumn{2}{|l|}{ BMI $\left(\mathrm{kg} / \mathrm{m}^{2}\right)$} & \multicolumn{2}{|c|}{50.1 (range: $40-62$ ) } \\
\hline \multirow[t]{2}{*}{ Reflux esophagitis; n (\%) } & Symptomatic & \multicolumn{2}{|c|}{$47(88.6)$} \\
\hline & Asymptomatic & \multicolumn{2}{|c|}{$6(11.4)$} \\
\hline Pathologic obesity; n (\%) & & \multicolumn{2}{|c|}{$5(9.4)$} \\
\hline History of DVT; n (\%) & & \multicolumn{2}{|c|}{$3(5.6)$} \\
\hline History of Diabetes; n (\%) & & \multicolumn{2}{|c|}{$9(16.9)$} \\
\hline History of hypertension; $\mathrm{n}(\%)$ & & \multicolumn{2}{|c|}{$11(20.7)$} \\
\hline History of OSA; n (\%) & & \multicolumn{2}{|c|}{$5(9.4)$} \\
\hline
\end{tabular}

\subsection{Postoperative}

Two patients who developed prolonged vomiting (3.7\%) were treated conservatively, 1 patient developed postoperative bleeding $(1.8 \%)$, exploration was done which revealed bleeding at staple line, and no patients developed leaks or stricture (0\%). Mortality rate was nil $(0 \%)$ (Table 2). EWL; the mean EWL at 6 months postoperatively was $46.3 \%$ (range $42.7-51.2 \%$ ), at 12 months was $54 \%$ (range $45.8-60.1 \%$ ), at 18 months was $61 \%$ (range 55-66.3\%). Also, we found that, preoperative co-morbidities are resolved by (53\%) and improved by (23\%). Post-operatively; reflux symptoms were absent in 30 patients (56\%), improved in 14 patients (26.4\%), but persistent in 7 patients $(13.2 \%)$.

Table 2. Operative and early post-operative data

\begin{tabular}{|l|l|}
\hline Parameter & Value \\
\hline Operative time (min) & 115 (range 90-180) \\
\hline Postoperative bleeding; $\mathrm{n}(\%)$ & $1(1.8)$ \\
\hline Postoperative leak; $\mathrm{n}(\%)$ & $0(0)$ \\
\hline Postoperative stricture; $\mathrm{n}(\%)$ & $0(0)$ \\
\hline Mortality rate; $\mathrm{n}(\%)$ & $0(0)$ \\
\hline Prolonged vomiting; $\mathrm{n}(\%)$ & $2(3.7)$ \\
\hline Postoperative hospital stay (day) & 4.2 (range: $3-6)$ \\
\hline
\end{tabular}

\section{Discussion}

The general consensus that LSG is a purely restrictive procedure is going through a gradual change. Presently, it is accepted that changes in gastric emptying and the reduction of large parts of the ghrelin-producing stomach mass could account for its success in terms of loss of weight and sustained decrease of hunger, compared with other restrictive procedures. About $15 \%$ of morbid obese patients suffer from hiatus hernia, and symptomatic reflux is diagnosed in about $50-70 \%$ of patients with a BMI $>35 \mathrm{~kg} / \mathrm{m}^{2}$. Morbid obesity has been proven to be an independent risk factor for HH and gastroesophageal reflux disease (12). LSG is considered to be an effective and a 
safe bariatric procedure with similar results to those of LRYGBP, in terms of weight loss it is superior to Laparoscopic Adjustable Gastric Band (LAGB), and has a low rate of postoperative morbidity (13). Patients undergoing LSG can develop symptoms of GERD, which indicates a common complication, although in a large number of patients, the incidence varies from $2.1 \%$ to $24.9 \%$. This could be due to the anatomic disruption of the angle of His and the changes in the rate of gastric emptying $(14,15)$. For the first few months following LSG, symptoms of GERD can be quite common, however with Proton Pump inhibitor (PPI) treatment, they can be regulated, and appear to gradually decrease over a period of time. Furthermore, improvement of GERD through LSG can be seen in $40-85 \%$ of patients who present clinical signs of GERD before surgery. This could be accountable to loss of weight following surgery, but the increase of the gastric compliance and emptying should also be considered as a cause. Reduction of gastric intraluminal pressure is aided by preservation of the antrum and the normal gastric emptying process through the pylorus (17). The position and function of the lower esophageal sphincter can be restored and also the GERD symptoms can be improved by restoring the stretched hiatus to normal by hiatoplasty. Similar to the literature there is a female predominance, Belanger et al., (81\%) (19), Jossart (78\%) (20), Lakdawala et al. (63\%) (21); in our study, we found that, there is also a female predominance (73.6\%). Obesity is associated with many co-morbidities, including hypertension, diabetes mellitus, heart disease, reflux esophagitis, OSA and others (Walsh, 2010) (2). In the current study, patients with DM were (16.9\%), with hypertension were (20.7\%), with OSA (9.4\%). Soliman et al. (22) reported that the mean operative time in a study on 20 patients was 95minutes (range 65-125 min); in our study, the mean operative time was $115 \mathrm{~min}$. As expected, the operative time was longer in patients with high BMI. Average hospital stay was (4.2 days) in the current study. Shah et al. (23) recorded that, average hospital stay was (3.5 days) while in the study of Himpens et al. (24) was (2.2 days). In a Spanish registry, investigators reported outcomes of 17 centers for 540 patients who had undergone LSG, the overall morbidity rate was $5.2 \%$ and mortality rate was $0.36 \%$ (25). A national registry in Germany was created to collect data on 144 LSG procedures performed at 17 hospitals; the overall rate of major complications was $9.4 \%$ (26). Lee et al. (27) reported the results of 216 patients who underwent LSG, complications occurred in $7.4 \%$ and no mortality was reported. Hamoui et al. (28) performed a study on 118 patients (115 open SG and 3 LSG), the morbidity was $15.3 \%$ and mortality was $0.85 \%$. In the current study, the overall morbidity was $5.6 \%$ ( 1 patient developed postoperative bleeding (1.8\%), 2 patients developed prolonged vomiting $(3.7 \%)$ and no mortality was reported. LSG is now being performed more frequently given the satisfactory weight loss results not only in the short-term, but also in the mid-term with shorter operating times and absence of need to create anastomosis (7). Karamanakos et al. (29), in the comparison of LSG to LRYGB, showed there was a larger percent excess weight loss at 12 months with LSG (69.7\% versus $60.5 \%$ ). Another prospective study comparing LSG with LAGB by Himpens et al. (30) reported better results in terms of weight loss for LSG, Median EWL at 1 year was $57.7 \%$ after LSG and $41.4 \%$ after LAGB; and at 3 years, was $66 \%$ versus $48 \%$ respectively. LSG was also effective in super-super obese and super obese according to Langer et al. (31), they reported that, mean EWL was $46 \%$ at 6 months, $56 \%$ at 12 months and $57 \%$ at 18 months. Peterli et al. (32), reported the results of 120 patients who underwent LSG, mean excess BMI loss was $62 \%$ at 1 year and $64 \%$ at 2 years in morbidly obese and super obese patients. In the current study; during the period of follow up; reflux symptoms were absent in 30 patients (56\%), improved in 14 patients (26.4\%), but persistent in 7 patients $(13.2 \%)$. Soliman et al. (22) reported that; postoperative symptomatic relieve of reflux was $65 \%$, postoperative symptomatic improvement of reflux was $25 \%$ while persistence of GERD after LSG and crural repair was in 10\% of patients. A complete assessment on all English literature on LSG comprising 1,163 patients, revealed a mean EWL percentage following LSG, ranging from $35 \%$ to $71.6 \%$ at 6 months, $45 \%$ to $83 \%$ at 1 year, $47 \%$ to $83 \%$ at 2 years and $66 \%$ at 3 years (7). The mean EWL in our study was: at 6 months $46.3 \%$, at 12 months $54 \%$ and at 18 months $61 \%$. Improvement of health status and resolution of co-morbidities such as diabetes, hypertension, OSA and dyslipidemia can be associated with LSG. Peterli et al. (32) and Rosenthal et al. (33) reported that, remission rates of type II diabetes after LSG were ranged between $60 \%$ and $80 \%$, depending on the patient population and length of follow up. A study by Silecchia et al. revealed that $60 \%$ of major co-morbidities were resolved and 24\% were improved in 41 super-obese patients following LSG. The study also showed a reduction in the operative risk (ASA) score, following LSG. In the current study, associated co-morbidities were resolved by $53 \%$ and improved by $23 \%$.

\section{Conclusions}

Laparoscopic Sleeve Gastrectomy was initially used as the first part of a two part procedure, but now LSG may represent a safe, easy and effective primary procedure to achieve significant weight loss, as well as significant improvement or resolution of major obesity related co-morbidities, with a low mortality and morbidity. Laparoscopic crural closure, during LSG, represents a valuable option for the treatment of morbid obesity and gastresophageal reflux, and can result in good outcomes in terms of GERD symptoms control. 


\section{Acknowledgments:}

The author is thankful to the Al-Azhar University Hospital (Egypt) for supporting this study.

\section{Conflict of Interest:}

There is no conflict of interest to be declared.

\section{References:}

1) Hoppin AG. Obesity and the liver: developmental perspectives. Semin Liver Dis. 2004; 24(4): 381-7. doi: 10.1055/s-2004-860867. PMID: 15605306.

2) Walsh J. Sleeve gastrectomy as a stand alone bariatric procedure for obesity. California Technology Assessment Forum. 2010; 13: 1-25.

3) El-Serag HB, Ergun GA, Pandolfino J, Fitzgerald S, Tran T, Kramer JR. Obesity increases oesophageal acid exposure. Gut. 2007; 56(6): 749-55. doi: 10.1136/gut.2006.100263. PMID: 17127706, PMCID: PMC1954847.

4) Hampel H, Abraham NS, El-Serag HB. Meta-analysis: obesity and the risk for gastroesophageal reflux disease and its complications. Ann Intern Med. 2005; 143(3): 199-211. doi: 10.7326/0003-4819-143-3200508020-00006. PMID: 16061918.

5) Morgenthal CB, Lin E, Shane MD, Hunter JG, Smith CD. Who will fail laparoscopic Nissen fundoplication? Preoperative prediction of long-term outcomes. Surg Endosc. 2007; 21(11): 1978-84. doi: 10.1007/s00464-007-9490-7. PMID: 17623236.

6) Maggard MA, Shugarman LR, Suttorp M, Maglione M, Sugerman HJ, Livingston EH, et al. Meta-analysis: surgical treatment of obesity. Ann Intern Med. 2005; 142(7): 547-59. doi: 10.7326/0003-4819-142-7200504050-00013. PMID: 15809466.

7) Trelles N, Gagner M. Updated review of sleeve gastrectomy. The Open Gastroenterology J. 2008; 2(1): 41 9. doi: 10.2174/1874259900802010041.

8) Strain GW, Gagner M, Inabnet WB, Dakin G, Pomp A. Comparison of effects of gastric bypass and biliopancreatic diversion with duodenal switch on weight loss and body composition 1-2 years after surgery. Surg Obes Relat Dis. 2007; 3(1): 31-6. doi: 10.1016/j.soard.2006.09.002. PMID: 17116424.

9) Rosenthal RJ. International sleeve gastrectomy expert panel consensus statement: best practice guidelines based on experience of $>12,000$ cases. Surg Obes Relat Dis. 2011; 1: 12. doi: 10.1016/j.soard.2011.10.019.

10) Brethauer SA, Hammel JP, Schauer PR. Systematic review of sleeve gastrectomy as staging and primary bariatric procedure. Surg Obes Relat Dis. 2009; 5(4): 469-75. doi: 10.1016/j.soard.2009.05.011. PMID: 19632646.

11) Uglioni B, Wolnerhanssen B, Peters T, Christoffel-Courtin C, Kern B, Peterli R. Midterm results of primary vs secondary laparoscopic sleeve gastrectomy (LSG) as an isolated operation. Obes Surg. 2009; 19(4): 401-6. doi: 10.1007/s11695-009-9804-z. PMID: 19169763.

12) Granderath FA, Carlson MA, Champion JK, Szold A, Basso N, Pointner R, et al. Prosthetic closure of the esophageal hiatus in large hiatal hernia repair and laparoscopic antireflux surgery. Surg Endosc. 2006; 20(3): 367-79. doi: 10.1007/s00464-005-0467-0. PMID: 16424984.

13) Perry Y, Courcoulas AP, Fernando HC, Buenaventura PO, McCaughan JS, Luketich JD. Laparoscopic Roux-en-Y gastric bypass for recalcitrant gastroesophageal reflux disease in morbidly obese patients. JSLS. 2004; 8(1): 19-23. PMID: 14974657, PMCID: PMC3015506.

14) Frezza EE, Ikramuddin S, Gourash W, Rakitt T, Kingston A, Luketich J, et al. Symptomatic improvement in gastroesophageal reflux disease (GERD) following laparoscopic Roux-en-Y gastric bypass. Surg Endosc. 2002; 16(7): 1027-31. doi: 10.1007/s00464-001-8313-5. PMID: 11984683.

15) Salvador-Sanchis JL, Martinez-Ramos D, Herfarth A, Rivadulla-Serrano I, Ibañez-Belenguer M, Hoashi JS. Treatment of morbid obesity and hiatal paraesophageal hernia by laparoscopic Roux-en-Y gastric bypass. Obes Surg. 2010; 20(6): 801-3. doi: 10.1007/s11695-008-9656-y. PMID: 18773250.

16) Patterson EJ, Davis DG, Khajanchee Y, Swanström LL. Comparison of objective outcomes following laparoscopic Nissen fundoplication versus laparoscopic gastric bypass in the morbidly obese with heartburn. Surg Endosc. 2003; 17(10): 1561-5. doi: 10.1007/s00464-002-8955-y. PMID: 12874685.

17) Zainabadi K, Courcoulas AP, Awais O, Raftopoulos I. Laparoscopic revision of Nissen fundoplication to Roux-en-Y gastric bypass in morbidly obese patients. Surg Endosc. 2008; 22(12): 2737-40. doi: 10.1007/s00464-008-9848-5. PMID: 18363066. 
18) Greenstein RJ, Nissan A, Jaffin B. Esophageal anatomy and function in laparoscopic gastric restrictive bariatric surgery: implications for patient selection. Obes Surg. 1998; 8(2): 199-206. doi: 10.1381/096089298765554818. PMID: 9730394.

19) Bellanger DE, Greenway FL. Laparoscopic sleeve gastrectomy, 529 cases without a leak: short-term results and technical considrations. Obes Surg. 2011; 21(2): 146-50. doi: 10.1007/s11695-010-0320-y. PMID: 21132397.

20) Jossart GH. Complications of sleeve gastrectomy: bleeding and prevention. Surg Laparosc Endosc Percutan Tech. 2010; 20(3): 146-7. doi: 10.1097/SLE.0b013e3181e3558b. PMID: 20551810.

21) Lakdawala MA, Bhasker A, Mulchandani D, Goel S, Jain S. Comparison between the results of laparoscopic sleeve gastrectomy and laparoscopic Roux-en-Y gastric bypass in Indian population: a retrospective 1 year study. Obes Surg. 2010; 20(1): 1-6. doi: 10.1007/s11695-009-9981-9. PMID: 19802646.

22) Soliman A, Maged H, Awad A, El-Shiekh O. Laparoscopic Crural Repair With Simultaneous Sleeve Gastrectomy: A Way in Gastroesophageal Reflux Disease Treatment Associated With Morbid Obesity. J Minim Invasive Surg Sci. 2012; 1(2): 67-73. doi: 10.17795/minsurgery-5171.

23) Shah PS, Todkar JS, Shah SS. Effectiveness of laparoscopic sleeve gastrectomy on glycemic control in obese Indians with type II diabetes mellitus. Surg Obes Relat Dis. 2010; 6(2): 138-41. doi: 10.1016/j.soard.2009.06.007. PMID: 19733515.

24) Himpens J, Dobbeleir J, Peeters G. Long-term results of laparoscopic sleeve gastrectomy for obesity. Ann Surg. 2010; 252(2): 319-24. doi: 10.1097/SLA.0b013e3181e90b31. PMID: 20622654.

25) Sánchez-Santos R, Masdevall C, Baltasar A, Martínez-Blázquez C, García Ruiz de Gordejuela A, Ponsi E. Short- and mid-term outcomes of sleeve gastrectomy for morbid obesity: the experience of the Spanish Natinal Registry. Obes Surg. 2009; 19(9): 1203-10. doi: 10.1007/s11695-009-9892-9. PMID: 19572113.

26) Stroh C, Birk D, Flade-Kuthe R, Frenken M, Herbig B, Höhne S, et al. Results of sleeve gastrectomy: data from a nationwide survey on bariatric surgery in Germany. Obes Surg. 2009; 19(5): 632-40. doi: 10.1007/s11695-009-9801-2. PMID: 19184256.

27) Lee CM, Cirangle PT, Jossart GH. Vertical sleeve gastrectomy for morbid obesity in 216 patients: report of two-years results. Surg Endosc. 2007; 21(10): 1810-6. doi: 10.1007/s00464-007-9276-y. PMID: 17356932.

28) Hamoui N, Anthone GJ, Kaufman HS, Crookes PF. sleeve gastrectomy in high-risk patients. Obes Surg. 2006; 16(11): 1445-9. doi: 10.1381/096089206778870157. PMID: 17132409.

29) Karamanakos SN, Vagenas K, Kalfarentzos F, Alexandrides TK. Weight loss, appetite suppression and changes in fasting and postprandial ghrelin and peptide-YY levels after Roux-en-Y gastric bypass and sleeve gastrectomy: a prospective, double blind study. Ann Surg. 2008; 247(3): 401-7. doi: 10.1097/SLA.0b013e318156f012. PMID: 18376181.

30) Himpens J, Dapri G, Cadiere GB. A prospective randomized study between laparoscopic gastric banding and laparoscopic isolated sleeve gastrectomy: results after 1 and 3 years. Obes Surg. 2006; 16(11): 1450-6. doi: 10.1381/096089206778869933. PMID: 17132410.

31) Langer FB, Bohdjalian A, Felberbauer FX, Fleischmann E, Reza Hoda MA, Ludvik B, et al. Does gastric dilatation limit the success of sleeve gastrectomy as a sole operation for morbid obesity? Obes Surg. 2006; 16(2): 166-71. doi: 10.1381/096089206775565276. PMID: 16469218.

32) Peterli R, Wölnerhanssen B, Peters T, Devaux N, Kern B, Christoffel-Courtin C, et al. Improvement in glucose metabolism after bariatric surgery: comparison of laparoscopic Roux-en-Y gastric bypass and laparoscopic sleeve gastrectomy: a prospective randomized trial. Ann Surg. 2009; 250(2): 234-41. doi: 10.1097/SLA.0b013e3181ae32e3. PMID: 19638921.

33) Rosenthal R, Li X, Samuel S, Martinez P, Zheng C. Effect of sleeve gastrectomy on patients with diabetes mellitus. Surg Obes Relat Dis. 2009; 5(4): 429-34. doi: 10.1016/j.soard.2008.11.006. PMID: 19342307.

34) Silecchia G, Boru C, Pecchia A, Rizzello M, Casella G, Leonetti F, et al. Effectiveness of laparoscopic sleeve gastrectomy (first stage of biliopancreatic diversion with duodenal switch) on co-morbidities in super-obese high-risk patients. Obes Surg. 2006; 16(9): 1138-44. doi: 10.1381/096089206778392275. PMID: 16989696. 